\title{
Peer Review Workgroup Report
}

\author{
Lorena Barba, Nancy Davenport, Lacey Earle, Ann Gabriel, Mark. Newton, Abel Packer, Richard Price
}

\section{Abstract / Workgroup Question}

Building on the peer review workgroup's proposals from OSI2016, this workgroup will develop a broader and clearer description of peer review that considers the different needs for different stages of review, as well as discuss possibly emerging issues such as the need to promote uniform interpretation and enforcement of peer review definitions, and will develop proposals for moving forward.

\section{Desirable Properties}

In thinking through the future of peer review, we considered four properties that would be desirable in a peer review system:

\section{Moving from a 2-person-system to a many person system \\ Currently academic papers are peer re- viewed by $\sim 2$ people: a journal editor will send out a submission to two peer review- ers to solicit their thoughts.}

It would be beneficial if there was a peer review system, both pre-publication and post-publication, that encouraged readers to share their thoughts and evaluations of the paper. This is what we mean by a 'many person system.' This system is normally called "post-publication peer review," though it's worth noting that getting feedback from readers will work in fields where preprints and drafts are shared.

\section{Peer Review of code and data-sets} Historically, the only form of scholarly output that gets peer reviewed is the paper. Since peer review, and venue of pub- lication, is one of the primary means for academic promotion, there is no incentive to share data-sets and code. It would be beneficial to have a system that ensured peer review for these items, as that would incentivize academics to share them.

Closed vs. open; anonymous vs. signed We discussed the question of whether peer reviews should be kept private, which is the norm, or whether it would be preferable for them to be open. We also discussed the orthogonal distinction between the peer reviews being anonymous, which is the historical norm, or whether they should be signed (non-anonymous).

\section{Discoverability of all peer reviews on a paper throughout life-cycle}

We discussed the fact that if you are looking at a published paper, it would be advantageous to know if there are comments and peer reviews on a prior version of the paper, say a public pre-print.

\section{Case Studies}

We discussed some case studies of developments in peer review. These case studies are mentioned here only by way of ac-

(C) 2017 OSI2017 Peer Review Workgroup. This open access article is distributed under the Creative Commons Attribution 4.0 International License. This document reflects the combined input of the authors listed here (in alphabetical order by last name) as well as contributions from other OSI2017 delegates. The findings and recommendations expressed herein do not necessarily reflect the opinions of the individual authors listed here, nor their agencies, trustees, officers, or staff. 
knowledging they were part of our discussion, not by way of endorsement.

Journal of Open Source Software The Journal of Open Source Software was co-founded by one of the members of our group, Lorena Barba.
The way it works is that authors submit some code, and a one-page write up of what the code does. The code is then peer reviewed by people familiar with the relevant programming languages.

Here is an example of the one-page writeup:

Figure 1. Journal of Open Source Software: One Page Write-Up

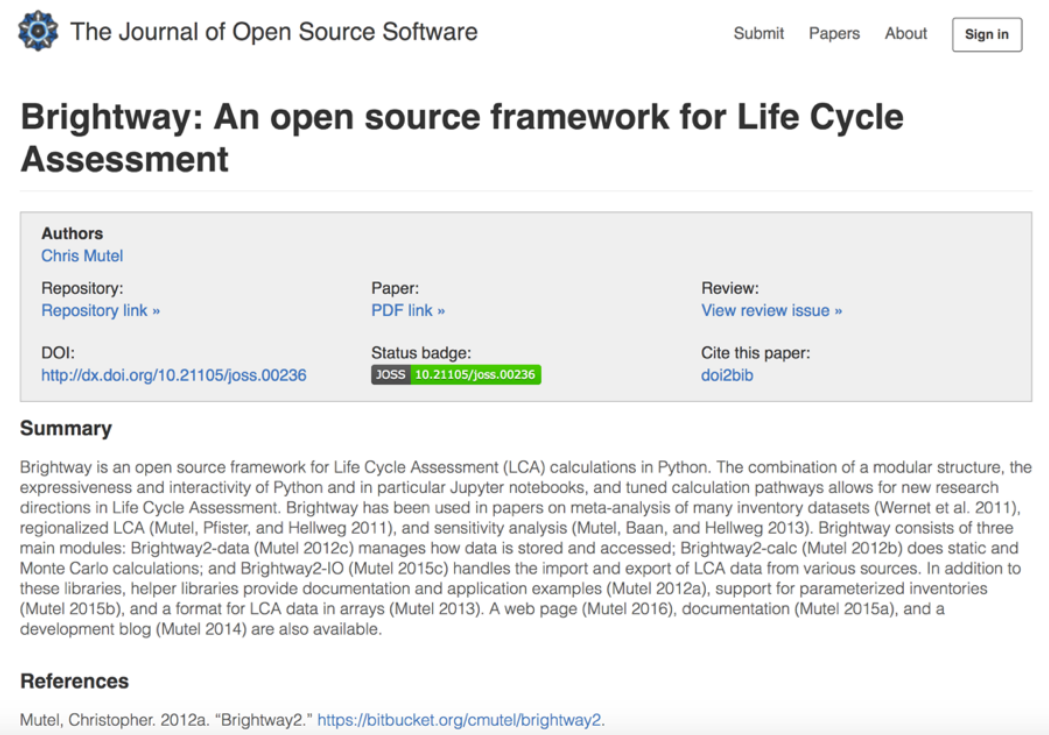


And here is an example of the list of pub-

lications:

Figure 2. Journal of Open Source Software: List of Publications

The Journal of Open Source Software

Submit Papers About Sign in

\section{The Journal of Open Source Software}

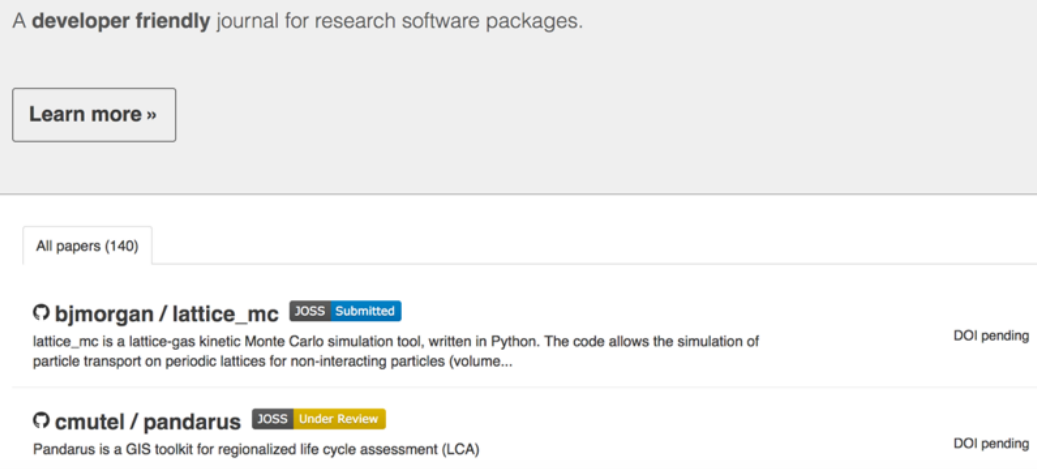

DOI pending

Academia.edu

Richard Price, the founder of academia.edu, was also a member of this group, and Richard described Academia.edu's Sessions feature. Sessions are a way for authors to crowd-source peer review on their draft papers. Sessions last 20 days, and the feedback on the paper appears on the right-hand margin of the paper.

Figure 3. Academia.edu: Example of "Sessions" Feature

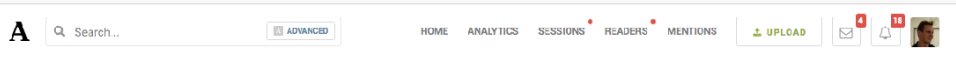

Pity the Poor Beast! Do Animals Have a Bad Life?

(अ) Downloaa (pat) $\quad \&$ Discussion

Pity the Poor Beast! Do Animals Have a Bad Life"?

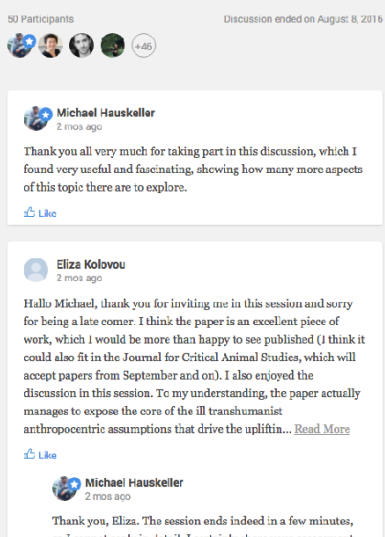

Ciarifzing the question

Do non-human animals ${ }^{1}$ have a bad life? Cleaily, very offen they do. They are being

mistreated in their millions, ard routinely used for various human purposes that gencrally

involve suffering and or death for the animals. Even if they live in the wild, free of human

interventicn, their lives may be pretty miserable, plagued by scarcity of food, too rany able

and hungry predaters, or tavaging discascs.

Yet the qirestion trat I wish to discciss when I am asking whether animals have a had life is

not whether they can have a bad life, nor wheher they very often do have a bad life, bu

rather wischer they necessarily have a tuad life, for the sole reason that they are animal

Let us imagine an animal that has the jest possitle life while still remaining an animal. Let us

Thank you, Elizas. The session ends indeed in a jew ninutes 
At the end of the 20 days, the session is closed, and no further comments are possible.

\section{Survey on Open/Closed and Anony- mous/Signed}

Ann Gabriel was in our group, and she shared some survey data that Elsevier had gathered on experiments around open and closed peer review.

Elsevier tried open peer review for five journals: peer reviewers were told in advance that their peer reviews will be published openly, alongside the paper. Furthermore, peer reviewers will have the choice whether to sign their public peer reviews, or keep them private.

After the experiment, peer reviewers were surveyed for their opinions. There were 40 respondents:

- 95 percent said publishing review reports didn't influence their recommendation.

- 45 percent provided consent to reveal their names.

- 98 percent said they will accept further review invites for the journal.

Other data included:

- 10 out of 14 peer reviewers thought that publishing of peer reviews should become common practice.

- 70 percent of editors said the reports are more in depth and constructive.

- 40 percent of editors said that the peer review reports are more helpful to make their decision.

\section{Further Questions}

Some questions that we thought warranted further discussion were:

More modern formats like HTML to allow more seamless commenting When papers are published in HTML form, in-line comments are possible, which are not possible with formats like PDF.

Formalization of open peer reviews: citable via DOIs

When open peer reviews can be cited, there will be more incentive for peer reviews to be open.

TOP-like framework to think about open/closed spectrum

The TOP framework is a series of standards that correspond to greater degrees of data transparency guidelines that a given journal might have. For example, level 1 means that a journal will state whether data is available for a given paper; level 2 means that data is posted to a trusted $3^{\text {rd }}$ party data repository; level 3 means that the study has been replicated by an independent $3^{\text {rd }}$ party prior to publication.

There was a question about whether a similar set of steps could be drawn up for levels of openness for peer review.

Areas of agreement/disagreement Nearly everyone agrees on the importance of peer review. It is so important, in fact, that questionable journals and unscrupulous researchers can invest considerable time and effort in fake peer review. Alternatively, some "predatory" journals forego peer review, yet claim to apply it. 
Most stakeholders also agree that reviewers are fatigued with requests and that it's increasingly difficult for journals to secure reviews. This contributes to the long delays for publication.

Some disagreement persists about what is peer review: for example, does it count if the review is completed by the editor(s) only? Some claim that is not peer review, others maintain that it is.

A fundamental disagreement between publishers and some researchers refers to whether peer review itself is enough of an "added value" to justify journal subscription costs. Dissenting researchers hold that peer review is accomplished by volunteer labor; publishers claim the administration of peer review is laborious and costly.

Within the researcher community, there is disagreement about the value of anonymity in peer review, the need for transparency, and how reviewers could be rewarded for their labor. A detectable trend towards double-open peer review (author and reviewer identities are both known to each other) has begun, but remains fringe. On the opposite end, some communities are going to great lengths to implement double-blind peer review. Transparent processes may include fully open review reports, published alongside the article.

Finally, broader adoption of open peer review-where reviewer reports and author responses are published alongside the article-could offer an antidote to shady journals claiming to do peer review, when they in fact do not. It may also offer an opportunity for reviewer recognition (if, for example, review reports themselves get a DOI and are citable). But delicate issues remain to be confronted: for exam- ple, how to deal with rejections. Neither reviewers nor authors likely want the review reports of rejected papers to be public. Also, some stakeholders have legitimate concerns about early career researchers suffering future reprisals for critical reviews of senior or established authors. Many fields have small communities, where non-anonymity of peer review could damage professional networks.

\section{Recommendations}

Peer review is an active area of reform in scholarly communication. It would be premature to endorse any one solution or best path forward. Rather, the best course of action for this community will be to support continued investigation into and experimentation with new methods, and weigh the pros and cons of each. This recommendation is consistent with the conclusions of the OSI 2016 peer review workgroup, which also encouraged continued study and experimentation.

More tangibly, what can help with this approach is the following:

1) Work as a community to define more clearly what is and isn't peer review, to impose an accepted standard that all journals will need to follow

2) Support or conduct studies that investigate the effectiveness of different modalities of peer review (open vs. closed, two-person vs. many, etc.) to help provide support and direction to the scholarly communication community as it experiments with different peer review systems

3) Aligned with the recommendations of the "What is Publishing?" (1) workgroup from OSI 2016, investigate the feasibility of publisher ser- 
vices disaggregation, whereby peer review (and other services such as editing) can be offered as a discrete service. Doing so would provide room for competition in the marketplace-in this case, room for other peer review systems to evolve (including those offered by publishers) while also potentially lowering the costs of subscription packages.

\section{Peer Review Workgroup}

Lorena Barba, Associate Professor of Mechanical and Aerospace Engineering, George Washington University

Nancy Davenport, University Librarian, American University

Lacey Earle, Vice President of Business Development, Cabell's

Ann Gabriel, Vice President Global Academic \& Research Relations, Elsevier

Mark Newton, Director of Digital Scholarship, Columbia University Libraries

Abel Packer, Co-founder and director, SciELO

Richard Price, Founder and CEO, academia.edu 